\title{
PROJETOS INTEGRADORES COMO UNIDADE CURRICULAR OBRIGATÓRIA EM CURSOS DE EDUCAÇÃO PROFISSIONAL: A ADERÊNCIA DAS PRÁTICAS EDUCATIVAS AO MODELO PEDAGÓGICO SENAC ${ }^{1}$
}

\section{Anderson Pena* \\ Daniela Papelbaum**}

* Psicólogo e Doutor em Educação. Assessor Técnico do Departamento Nacional do Senac e Professor do Ensino Superior. Rio de Janeiro, Rio de Janeiro, Brasil. E-mail: anderson. pena@senac.br

** Gerente de Desenvolvimento Educacional da Diretoria de Educação Profissional do Departamento Nacional do Senac. Rio de Janeiro, Rio de Janeiro, Brasil. E-mail: daniela.papelbaum@ senac.br

Recebido para publicação em: 9.10.2018

Aprovado em: 13.11.2018

\section{Resumo}

0 artigo mostra os resultados de pesquisa quantitativa e qualitativa com 2.221 docentes atuantes na implementação do novo Modelo Pedagógico Senac em todo o Brasil. Com média nacional de 8,33 pontos de aderência das práticas pedagógicas Unidades Curriculares Projeto Integrador nos cursos, foi possível concluir que os Projetos Integradores vêm sendo implementados a contento nos Departamentos Regionais. Recomendam-se a expansão de ações de formação continuada e o desenvolvimento de estratégias nacionais que fomentem a inovação pela via dos projetos.

Palavras-chave: Projeto Integrador. Metodologias ativas. Educação profissional.

\section{Introdução}

O Departamento Nacional do Senac, em conjunto com os Departamentos Regionais, iniciou, em 2013, uma importante ação de alinhamento nacional da oferta de educação profissional nos cursos de Aprendizagem, Qualificação Profissional e Habilitação Profissional Técnica de Nível Médio, denominada de Modelo Pedagógico Senac (MPS) (SENAC, 2015c). O MPS apresenta, nesse sentido, um conjunto de concepções orientadoras das práticas educativas realizadas no Senac alinhadas à missão institucional de educar para o trabalho em atividades do comércio de bens, serviços e turismo.

A organização dos cursos em estruturas curriculares cuja competência é a própria Unidade Curricular (UC), expressas em Planos de Cursos Nacionais, as Marcas Formativas Senac ${ }^{2}$, os referenciais para avaliação e, em especial, a inserção de Projetos Integradores (PI) como UCs obrigatórias dos cursos são aspectos centrais do Modelo. Em especial, o PI refere-se a uma prática educativa fundamentada nas metodologias ativas da aprendizagem, cujo princípio é a articulação de competências, por meio de interações sociais 
e compartilhamento de experiências, na busca por soluções a desafios gerados no contexto da ocupação, objeto da formação profissional.

Em 2017, mais de 250 mil matrículas foram realizadas em cursos alinhados ao Modelo Pedagógico, atingindo, aproximadamente, $70 \%$ da oferta ${ }^{3}$. Ainda que esse percentual indique que a expansão do Modelo Pedagógico vem crescendo, em todo o país, há a necessidade de compreender como as práticas educativas são realizadas, no âmbito dos princípios e orientações do Modelo, e o quanto estão aderentes às suas premissas.

O objetivo desta pesquisa, portanto, tratou de compreender, a partir da percepção dos docentes, como a Unidade Curricular Projeto Integrador (UCPI), estratégica para a articulação das competências que integram o perfil profissional e o desenvolvimento das Marcas Formativas Senac, vem sendo realizada em todo o Senac. Sobretudo, buscou-se quantificar, em um indicador sintético, o quanto a percepção e as práticas docentes estão aderentes aos pressupostos de desenvolvimento dos PIs nos cursos alinhados ao MPS.

Há a necessidade de se compreender como as práticas educativas são realizadas
Orientado por esse objetivo, este artigo expõe os resultados da pesquisa em seis partes. A primeira apresenta a Unidade Curricular de Natureza Diferenciada Projeto Integrador como aspecto integrante da organização curricular dos cursos do MPS. Na sequência, descreve-se o percurso metodológico da pesquisa. Nos itens seguintes são discutidos os resultados encontrados e, por último, apresentam-se as considerações finais e recomendações.

\section{A Unidade Curricular de Natureza Diferenciada Projeto Integrador}

O MPS, com o objetivo de propiciar experiências de aprendizagem significativas que se sustentem no "aprender fazendo" e no diálogo entre a sala de aula e o mundo do trabalho, buscou referências nas metodologias ativas da aprendizagem, sobretudo na Aprendizagem Baseada em Projetos (ABP), para a necessária articulação das competências dos perfis profissionais dos cursos e o desenvolvimento das Marcas Formativas Senac.

A ABP, cuja origem remonta ao movimento Escola Nova, surgida entre o fim do século XIX e o início do seguinte, no contexto da industrialização que se processava na Europa e na América do Norte, é uma abordagem pedagógica de caráter ativo e participativo, centrada em desafios que envolvem, para a sua solução, o desenvolvimento de todas as etapas de um projeto - planejamento, execução, monitoramento, avaliação e entrega. 0 início da experiência se dá, portanto, com a formulação de um problema desafiador, que não tenha resposta fácil e estimule a imaginação e criatividade. Diferentes conhecimentos, habilidades, atitudes e valores, assim como o trabalho em equipe, protagonismo e pensamento crítico, são articulados e mobilizados na busca por respostas. 
Na literatura sobre o assunto, é possível identificar diversos pesquisadores cujos trabalhos contribuíram para o avanço de propostas pedagógicas baseadas em projetos educacionais. Dentre eles, destacam-se os franceses Ovide Decroly e Celestin Freinet, além de Maria Montessori, na Itália, e, John Dewey, importante nome da Escola Nova nos Estados Unidos, e William Kilpatrick, seu discípulo (SENAC, 2015e). Os dois últimos, em especial, inovaram ao atribuir aos projetos educacionais a característica de instrumentos pedagógicos organizados de forma a proporcionar uma experiência significativa, fixada nos pressupostos de participação coletiva, estímulo à autonomia e tomada de decisão dos alunos (KILPATRICK, 1967).

Nesse sentido, dado o potencial da ABP em articular competências a partir de situações que envolvam pesquisa, testagem de hipóteses, tomada de decisões e trabalho em equipe para atingir os objetivos propostos, optou-se em trazer essa abordagem para a organização curricular dos cursos do MPS. Assim, a UCPI passou a ser obrigatória nos cursos de Aprendizagem Profissional Comercial, Qualificação Profissional, Habilitação Profissional Técnica de Nível Médio e suas respectivas certificações intermediárias. Para o desenvolvimento da UCPI, conforme o Documento Técnico Projeto Integrador ${ }^{4}$ (SENAC, 2015c), preveem-se as seguintes etapas, apresentadas na Figura 1:

Figura 1 - Etapas de desenvolvimento das UCPIs, segundo Documento Técnico

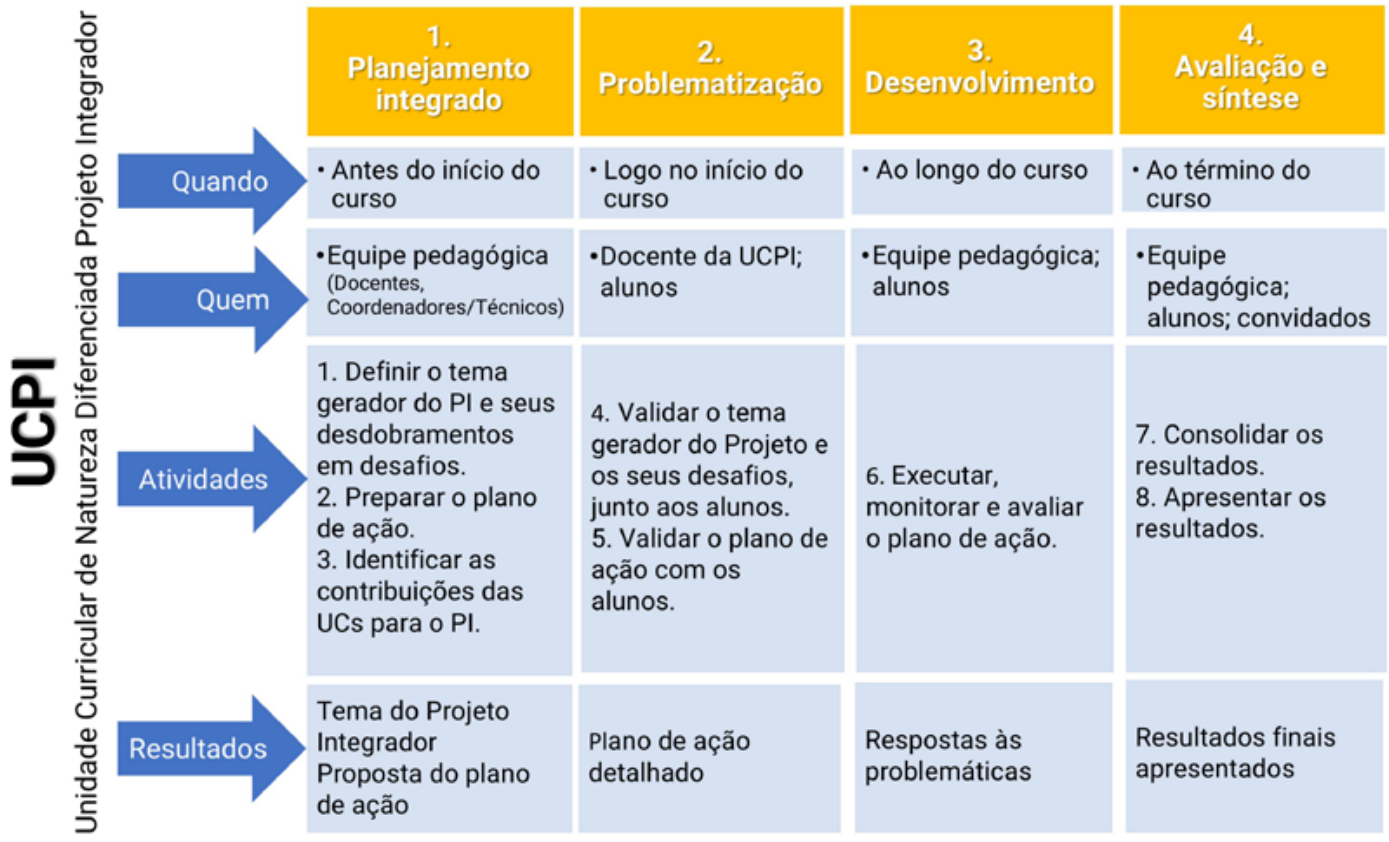

Fonte: Diretoria de Educação Profissional, Senac, Departamento Nacional. 
No aspecto organizativo, a UCPI apresenta carga horária específica (até 10\% da carga horária total do curso), docente responsável e Plano de Trabalho Docente (PTD) próprio, no qual são detalhadas as atividades a serem realizadas, além de indicadores e menções para avaliação dos alunos, ambos na perspectiva do MPS 5 . Sua execução ocorre ao longo de todo o processo formativo, o que the confere a característica de ser correquisito das demais Unidades Curriculares do Perfil Profissional, e impõe a necessidade de articulação dos docentes, em uma ação de planejamento integrado do curso, que preveja a realização de situações de aprendizagem ${ }^{6}$, em cada UC, que contribuam para a efetivação do PI. Nos Planos de Cursos Nacionais, são apresentadas sugestões de temas geradores para os Pls, o que não descarta adaptações regionais ou novas formulações que atendam às motivações dos alunos e docentes. Essas características atribuem aos PIs maior complexidade na realização, cuja eficácia estará diretamente ligada à efetiva participação coletiva e articulada entre equipe pedagógica e alunos.

Ciente dessa questão e, em concordância com políticas institucionais de formação continuada dos docentes, o Departamento Nacional, em conjunto com os Departamentos Regionais do Senac, vem, desde a implementação do Modelo Pedagógico, investindo na capacitação dos docentes em temas do Modelo, em especial, na orientação para a realização de PIs. A divulgação da Coleção de Documentos Técnicos do Modelo Pedagógico Senac7, a realização de cursos e oficinas e a orientação in loco dos supervisores e orientadores pedagógicos para o desenvolvimento de PIs são estratégias implementadas nessa direção. Se, por um lado, ações dessa natureza fazem parte do cotidiano do Senac, por outro lado, havia, até então, um hiato de informações sobre a maneira como os docentes vinham percebendo e implementando os PIs em todo o território nacional. O percurso metodológico e os resultados da pesquisa, tópicos apresentados a seguir, buscam contribuir para essa discussão.

\section{Metodologia}

O estudo utilizou a pesquisa quantitativa como método principal para coleta e análise dos dados de questionários on-line aplicados aos docentes de UCPI (ALVES-MAZZOTTI; GEWANDSZNAJDER, 2004). Essa opção metodológica se justifica pela necessidade de construir medidas indicativas da realização dos PIs nos Departamentos Regionais, de forma a se obter informações qualificadas para as estratégias de gestão da implementação do Modelo Pedagógico, o que caracteriza o desenho desse trabalho como pesquisa aplicada ${ }^{8}$.

A partir das bases prévias dos respondentes, encaminhadas pelos Departamentos Regionais, foi construído delineamento do plano amostral da pesquisa com o intuito de obter resultados com erro amostral ${ }^{9}$ de $2,5 \%$ em nível nacional e de até 5,0\% por Núcleo de Desenvolvimento Corporativo (Norte e Centro-Oeste; Sul-Sudeste; e Nordeste). 
Para a elaboração dos questionários on-line foram necessários três momentos: I) estudo da bibliografia e elaboração da matriz de itens; II) aplicação do pré-teste em docentes de três Departamentos Regionais, análise dos resultados e ajuste dos instrumentos; e III) desenvolvimento das versões on-line dos questionários no software Sphinx ${ }^{10}$.

Para a redação dos itens do questionário, tomaram-se por base as orienPretendeu-se verificar o grau de conformidade entre as práticas pedagógicas realizadas tações institucionais para realização de PIs, expressas no Documento Técnico Projeto Integrador (SENAC, 2015e). Para cada item, portanto, havia uma resposta esperada condizente com a sua devida orientação, expressa no Documento Técnico. Assim, o valor zero foi atribuído às respostas que não estavam de acordo com os parâmetros e o valor 1 , à resposta que estava de acordo. Como as assertivas foram medidas em uma escala de concordância com 5 gradações (discordo totalmente, discordo parcialmente, não concordo nem discordo, concordo parcialmente, concordo totalmente), consideraram-se respostas corretas aquelas nas quais os docentes concordaram parcial ou totalmente ${ }^{11}$.

Portanto, quanto mais a prática pedagógica assinalada no questionário pelo docente se aproximou da resposta esperada, maior a probabilidade de que a UCPI por ele ministrada tenha sido desenvolvida de maneira alinhada aos pressupostos do MPS. Essa lógica estrutural foi a base para a construção do indicador de aderência das UCPI. Para o cálculo desse indicador ( $\left.I_{\text {ader }}\right)$, levou-se em conta a média dos indicadores individuais de aderência das UCPIs alcançados pelos docentes, expressa na fórmula:

$$
\mathrm{I}_{\text {ader }}=\operatorname{méd}\left(I_{\text {ader }}\right) ; I_{\text {ader }}=\frac{\left(\sum_{i=1}^{17} x_{i}\right)}{17}
$$

Onde: $I I_{\text {ader }}$ corresponde ao indicador individual de aderência à metodologia de Projeto Integrador; $\mathbf{x}_{\mathbf{i}}$ representa a pontuação da assertiva.

Com essa medida, pretendeu-se verificar o grau de conformidade entre as práticas pedagógicas realizadas nas UCPIs e as recomendações metodológicas para desenvolvimento de PIs no Modelo Pedagógico, referenciadas no Documento Técnico Projeto Integrador. Após a aplicação, para levantamento das estatísticas descritivas e procedimentos de análises, foram utilizados métodos de validação e consistência interna das informações coletadas nos questionários (LAROS; PUENTE-PALACIOS, 2004; URBINA, 2007). No entanto, parte dos dados obtidos também passou por análise qualitativa, uma vez que as respostas dissertativas foram categorizadas, interpretadas e discutidas segundo sua natureza semântica (BARDIN, 2009; BOGDAN; BIKLEN, 1994; TUCKMAN, 2005). A partir desse percurso metodológico, construíram-se as análises apresentadas a seguir. 


\section{Perfil dos docentes de UCPI}

Foram encaminhados e-mails com o questionário para 2.779 docentes de UCPI dos Departamentos Regionais, no período de 19 de julho a 20 de agosto de 2017. No total, o Departamento Nacional recebeu 2.221 respostas, atingindo o percentual de $83 \%$ de participação. Os docentes de UCPI do Senac são, conforme os respondentes, predominantemente, do sexo feminino $(63,4 \%)$, na faixa etária entre 30 a 39 anos (42,8\%), pós-graduação completa $(70,6 \%)$ e com média de cinco anos de vínculo com o Senac.

Considerando que, na média nacional, os docentes têm cinco anos de vínculo empregatício com o Senac e que a implementação do Modelo Pedagógico se iniciou em 2015, ou seja, há três anos, é possível afirmar que a maior parte dos respondentes acompanha esse processo desde o seu início. Essa é uma constatação importante, porque reforça o grau de consistência das respostas, haja vista que a maioria dos docentes tem vivenciado as ações de implementação que vêm sendo realizadas nos Departamentos Regionais.

Vale destacar que o questionário também foi encaminhado para docentes de UCPI que já não compunham, no momento da pesquisa, o quadro de contratados do Senac, mas que, na época anterior à coleta de dados, desenvolveram PIs na Instituição e, portanto, constavam na base enviada pelos Departamentos Regionais. No total, 76 docentes desligados do Senac responderam ao questionário, representando $3,4 \%$ do total de respondentes.

\section{Formação continuada para atuação na UCPI}

o Departamento Nacional e os Departamentos Regionais do Senac realizam ações permanentes de formação continuada para os docentes, com o objetivo de fomentar o desenvolvimento técnico e o aprimoramento das práticas pedagógicas.

Assim, investigou-se, em relação à formação continuada oferecida pelo Departamento Nacional, a participação na Trilha de Formação Docente - curso de extensão na modalidade Educação a Distância (EAD), oferecido entre 2014 e 2017 - e na Especialização em Docência para Educação Profissional - curso de pós-graduação na modalidade EAD, iniciado em 2010 e com conteúdo atualizado após o início da implementação do MPS, sendo finalizado em 2017.

Em relação aos Departamentos Regionais, investigou-se a participação docente em oficinas, grupos de estudos, cursos, palestras e outras estratégias realizadas pelo Regional com a finalidade de abordar temas do MPS, sobretudo relacionados ao desenvolvimento de PIs.

No total nacional das ações de formação continuada ofertadas pelo Departamento Nacional (Trilha de Formação Docente e Especialização em Docência para Educação Profissional), 16,9\% participaram de ambas, 54\% dos respondentes participaram de forma parcial, ou seja, realizaram apenas uma dessas formações, 
e 29,1\% não participaram de nenhuma das ações de formação ofertadas pelo Departamento Nacional.

Das ações de formação continuada ofertadas pelos Departamentos Regionais, 56,9\% dos docentes afırmaram a participação. Entre esses, 18,3\% indicaram, ainda, ter participado de todas as formações e 38,6\%, de até duas ações de formação continuada ofertadas pelo Departamento Regional.

Além das ações de formação ofertadas pelo Departamento Nacional e pelos Regionais, os docentes também responderam, de maneira específica, sobre a leitura e o estudo da Coleção de Documentos Técnicos do Modelo Pedagógico Senac. Esse item foi considerado crucial para a análise dos resultados, já que a Coleção é a principal referência que embasa a prática docente no Modelo Pedagógico. Optou-se por identificar, em específico, o grau de conhecimento dos docentes acerca da Coleção de Documentos Técnicos propriamente dita, uma vez que esse material está disponibilizado desde o ano de 2015 e vem sendo continuamente recomendado como fundamental para o exercício da prática docente no Senac. Assim, dada a centralidade dos Documentos Técnicos para a prática docente no MPS, foi elaborada a hipótese de que, quanto maior o contato do docente com os Documentos Técnicos, maior a aderência das práticas pedagógicas realizadas na UCPI às premissas do Modelo Pedagógico. Do total de respondentes, 73,4\% afirmaram ter lido a Coleção de Documentos Técnicos do Modelo Pedagógico Senac.

A Figura 2, a seguir, apresenta a distribuição das respostas dos docentes quanto à leitura do Documento Técnico Projeto Integrador, por Núcleo de Desenvolvimento Corporativo:

Figura 2 - Leitura do Documento Técnico Projeto Integrador por Núcleo

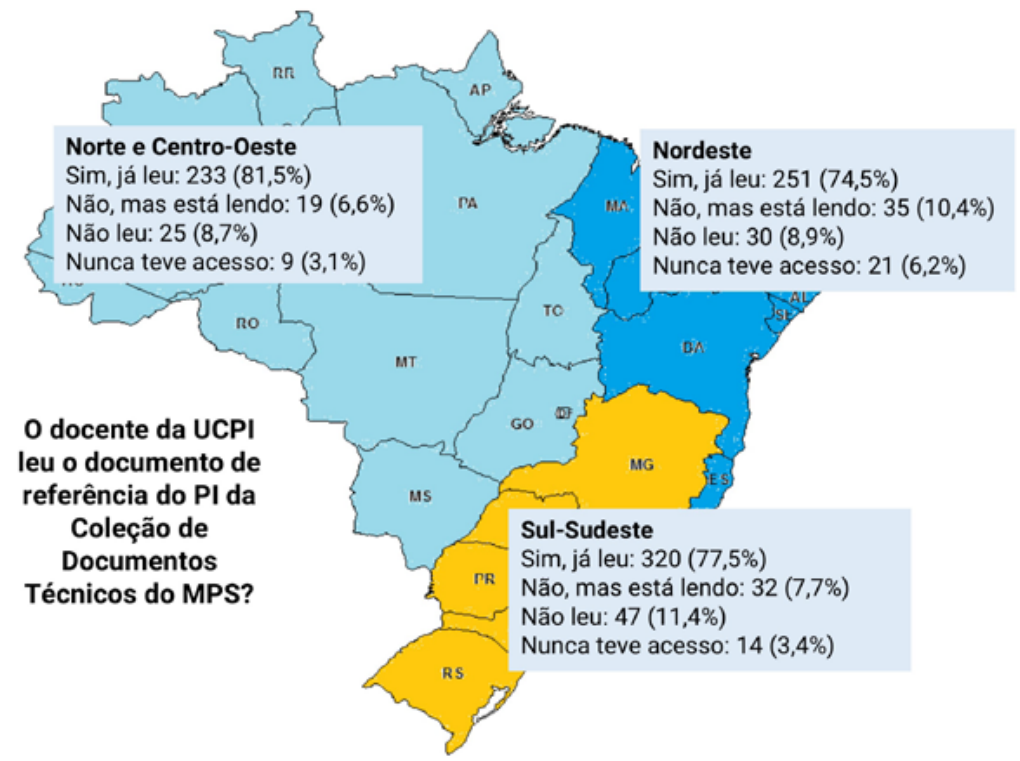

Fonte: Diretoria de Educação Profissional, Senac, Departamento Nacional. 
A maioria dos docentes participou de alguma ação de formação continuada e realizou a leitura do Documento Técnico Projeto Integrador. Essa constatação é um importante elemento indicativo de que os esforços de formação continuada, com o objetivo de capacitar o docente para atuar na UCPI, têm tido suficiente capilaridade nos Departamentos Regionais.

\section{Grau de aderência da UCPI ao MPS}

O Gráfico 1, a seguir, apresenta os resultados para o indicador de aderência das práticas pedagógicas realizadas na UCPI em âmbito nacional e por Núcleo de Desenvolvimento Corporativo, utilizando uma escala que vai de nenhuma aderência - representada pelo zero -, até total aderência ao MPS - representada pelo valor 10.

\section{Gráfico 1 - Aderência das práticas pedagógicas da UCPI ao MPS}

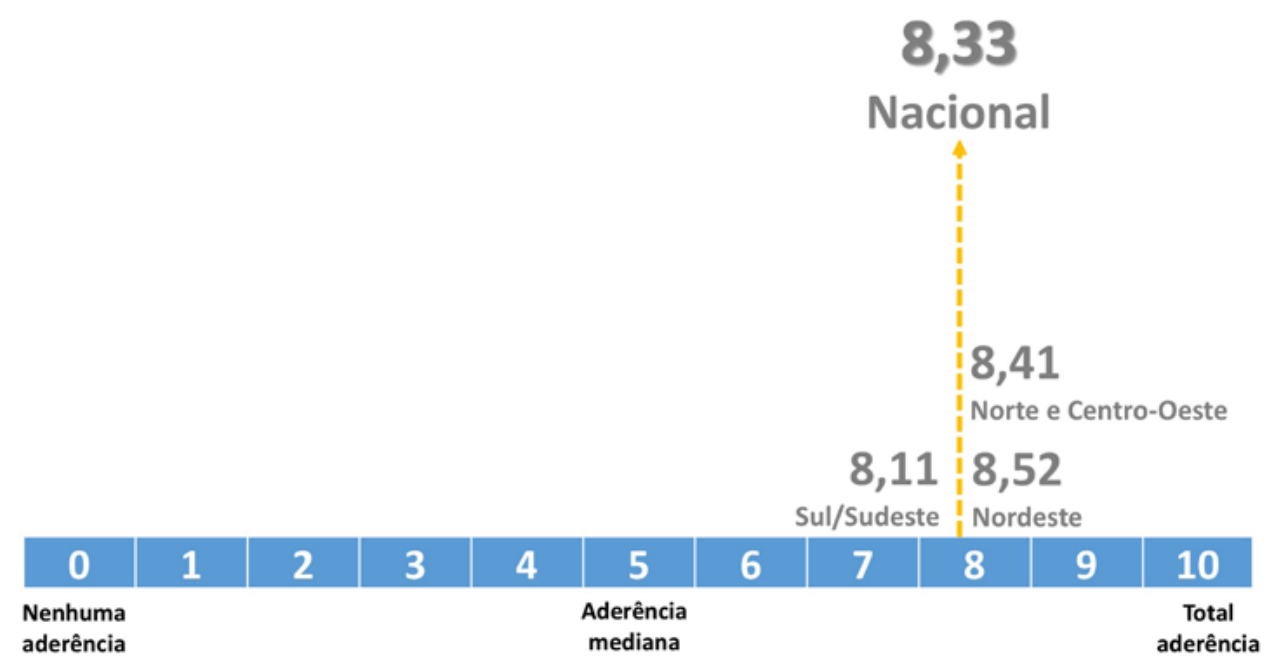

Fonte: Diretoria de Educação Profissional, Senac, Departamento Nacional.

O resultado de 8,33 pontos apresentado pelo indicador de aderência das práticas pedagógicas realizadas na UCPI em âmbito nacional pode ser interpretado como positivo para o terceiro ano da implementação do MPS, permitindo-se compreender que a UCPI está sendo desenvolvida com bastante aderência aos parâmetros esperados e de maneira muito similar entre os Núcleos de Desenvolvimento Corporativo. Confirma-se, portanto, a hipótese de que as ações de formação continuada e de estudo do Documento Técnico estejam produzindo resultados positivos no campo da sala de aula. Provavelmente, a orientação pedagógica conduzida pelas equipes técnicas nos Departamentos Regionais seja outra variável que possa ter contribuído para que as práticas de desenvolvimento de PIs, relatadas pela maioria dos docentes estejam em conformidade com os pressupostos do MPS. 
Outros aspectos qualitativos também devem ser considerados para a análise desse indicador. O primeiro reside no fato, já amplamente debatido na literatura sobre Teoria da Mudança ${ }^{12}$, de que, nas instituições submetidas a processos de mudança, é possível que haja forças de resistência e cessão, avanço e retrocesso, próprias do período em que novas formas de fazer são introduzidas no cotidiano de trabalho das instituições, representando quebra de paradigmas institucionais. Vale considerar, nesse ponto, que a implementação do MPS ainda está em andamento, com previsão de término para 2019, o que permite afirmar que o Senac está em pleno processo de mudança de suas práticas pedagógicas e que forças daquela natureza podem existir e, inclusive, interferir na operação do Modelo.

O segundo leva em conta que, com a sofisticação pedagógica dos Projetos Integradores, que pressupõem planejamento docente integrado, ampla participação coletiva e desenvolvimento em todas as demais UCs compostas de atividades com foco nas problemáticas do $\mathrm{PI}$, sem que isso represente acréscimo formal de carga horária da UCPI, era de se esperar que o corpo docente necessitasse de tempo para que as ações de formação continuada e prática efetiva apresentassem amadurecimento suficiente para consolidação de uma rotina pedagógica.

Esses aspectos combinados reforçam, ainda mais, a percepção de que, ao atingir o resultado de aderência observado nesse indicador, a prática pedagógica de desenvolvimento de Projetos Integradores no âmbito do Modelo Pedagógico seja, de fato, um importante salto qualitativo no incremento da oferta de educação profissional realizada no Senac. Importante ressaltar que o indicador apresenta uma visão panorâmica do fenômeno pedagógico, já que, quando analisado de forma detalhada, revela pontos que requerem atenção por parte dos Departamentos Regionais. Essa análise pormenorizada, com foco na dinâmica de desenvolvimento das UCPIs, é apresentada a seguir.

\section{Dinâmica de desenvolvimento das UCPIs}

0 planejamento integrado deve ocorrer antes do início das aulas
A dinâmica de desenvolvimento das UCPIs refere-se ao relato da prática dos docentes em cada uma das etapas de desenvolvimento dos PIs, bem como à percepção deles sobre a participação dos alunos e das demais UCs para a realização do PI.

\subsection{Planejamento integrado}

De acordo com o Documento Técnico Projeto Integrador, o planejamento integrado deve ocorrer antes do início das aulas, com o objetivo de "organizar, de forma colaborativa, as ações pedagógicas do curso e os objetivos de formação a serem alcançados" (SENAC, 2015e, p. 14).

Ao analisar os resultados, observa-se que essa prática vem, de fato, ocorrendo, conforme sinalizado pela maioria dos respondentes (81,5\%). De acordo com $63,4 \%$ dos 
docentes, a definição do tema gerador foi feita nessa etapa, e 87,5\% dos docentes afirmaram que as contribuições de cada UC foram feitas no planejamento integrado. Esses são aspectos positivos que reforçam a relevância do planejamento integrado como etapa de decisão e organização interna para a realização do PI.

A elaboração prévia do PTD pela equipe pedagógica é uma escolha estratégica do Departamento Regional. Para 66,4\% dos docentes, os seus PTDs foram, de fato, previamente elaborados pela equipe pedagógica. Cabe esclarecer que, ainda que o PTD possa ser previamente elaborado pela equipe pedagógica para estabelecer um padrão de qualidade das práticas a serem realizadas, orienta-se o docente para que as situações de aprendizagem sejam replanejadas de acordo com as necessidades e características da turma, o que pressupõe apoio e orientação pedagógica por parte das equipes técnicas do Departamento Regional.

\section{Figura 3 - Planejamento integrado segundo os docentes respondentes}

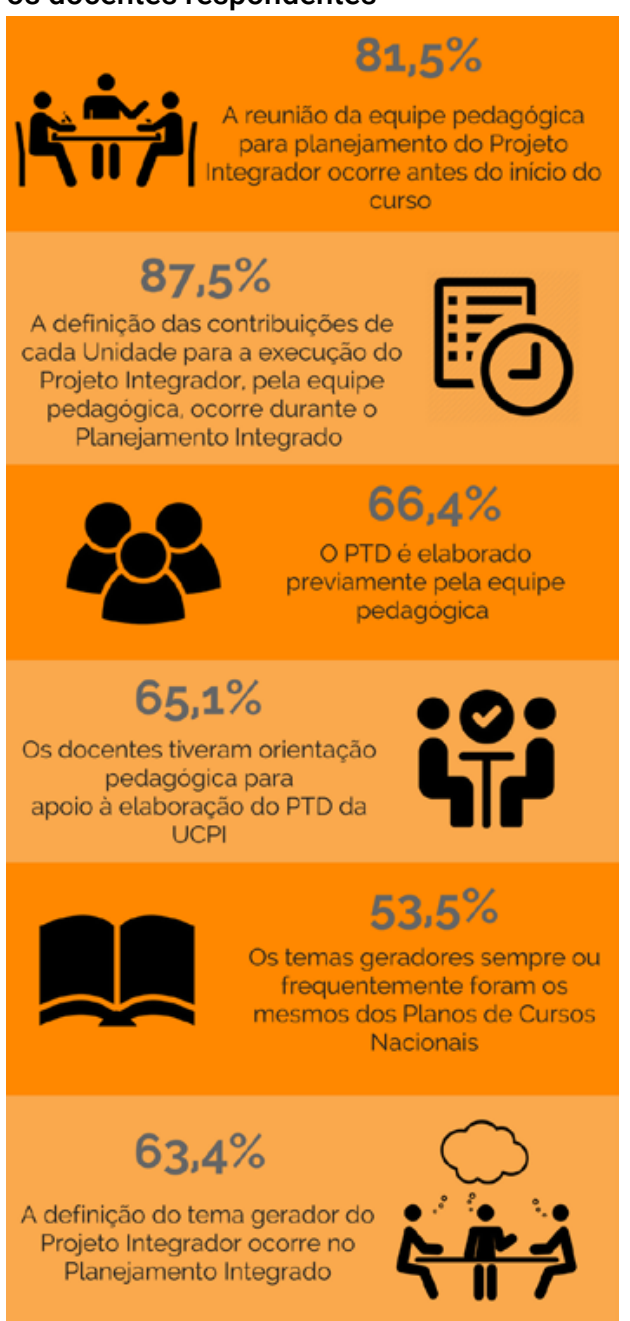

Fonte: Diretoria de Educação Profissional, Senac, Departamento Nacional.

\subsection{Desenvolvimento do PI}

Como correquisito das demais UCs, o PI deve ter início logo no começo do curso, sendo a etapa da problematização - realizada com os alunos - o ponto de partida para o seu desenvolvimento. Nessa etapa, devem ser debatidos, organizados e validados o tema do PI e seus desafios. Uma proposta de cronograma das atividades a serem realizadas pelos alunos também é elaborada nesse momento. Para a maior parte dos respondentes (83,9\%), em consonância com a orientação, o desenvolvimento do PI ocorre, efetivamente, logo no início do curso e, para $70,3 \%$, o cronograma foi, de fato, elaborado pelos alunos.

Ampla parcela dos respondentes, 93,1\%, concorda que os planos de entregas parciais ajudaram a acompanhar a execução dos Pls e $97,2 \%$ disseram ter proposto atividades para o desenvolvimento de Marcas Formativas, o que indica que esses pontos estão sendo realizados com sucesso pelos docentes de UCPI. No entanto, quando questionados sobre a suficiência dos recursos didático-pedagógicos disponíveis, pouco mais da metade $(53,1 \%)$ afirmou serem suficientes, o que abre um ponto de atenção sobre esse aspecto. 
Figura 4 - Desenvolvimento segundo os docentes respondentes

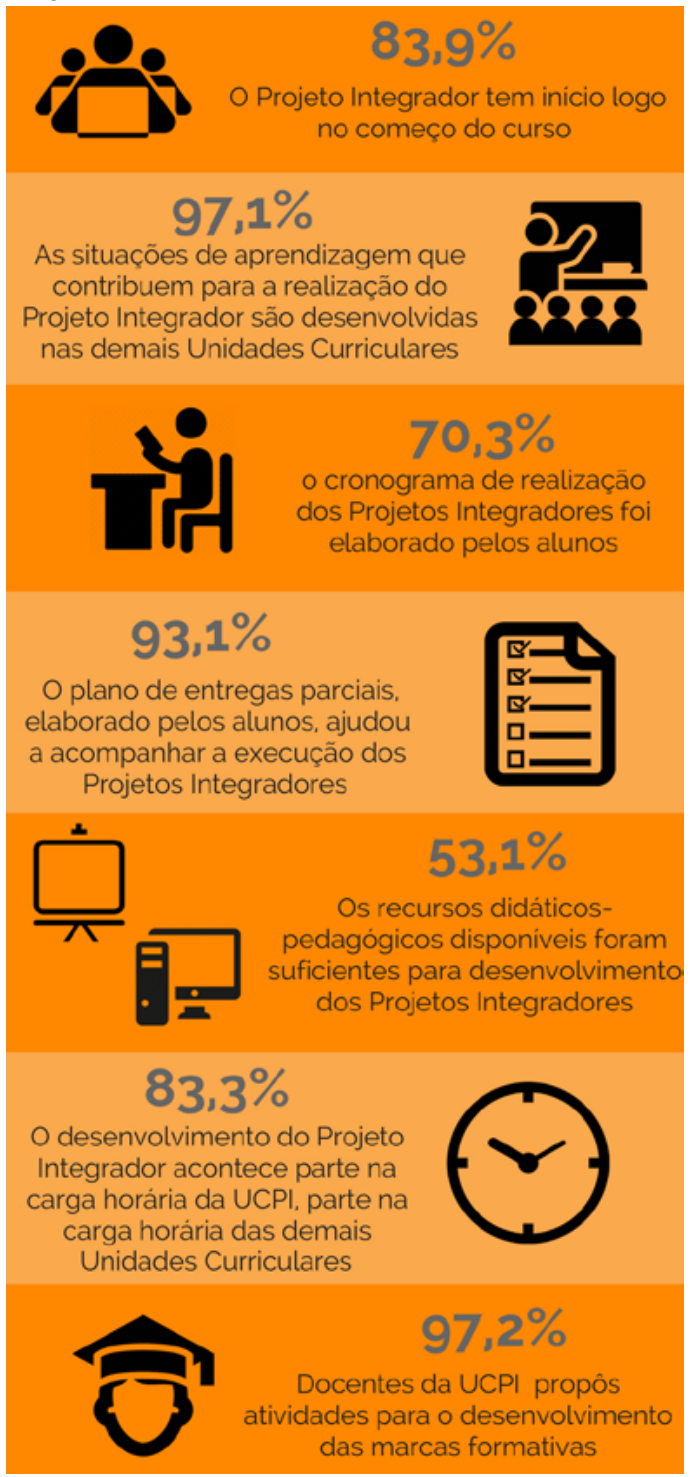

Fonte: Diretoria de Educação Profissional,

Senac, Departamento Nacional.

\subsection{Síntese e avaliação}

Segundo o Documento Técnico Projeto Integrador, a síntese é o momento de reflexão dos alunos sobre o percurso realizado para a resolução dos problemas e desafios apresentados no decorrer do projeto; já a avaliação é feita por meio de indicadores específicos ao longo da UCPI.

Além de avaliar os alunos com base nos indicadores, os docentes devem também identificar: a evidência das Marcas Formativas Senac na resolução dos desafios apresentados; a articulação das competências do curso no desenvolvimento do Pl; a elaboração e síntese do PI, respondendo às especificações do tema gerador; e a apresentação dos resultados do PI com coerência e criatividade, propondo soluções inovadoras a partir da visão crítica da atuação profissional no segmento (SENAC, 2015e, p. 21).

Observa-se, pelos resultados, que a quase totalidade dos docentes afirmou ser possível avaliar individualmente os alunos a partir dos indicadores propostos $(92,6 \%)$. De acordo com $97,5 \%$ dos docentes, os alunos apresentaram respostas adequadas às problemáticas e desafios; já $85,9 \%$ afirmaram que os alunos divulgaram em diversos suportes e meios de comunicação os resultados encontrados.

Para 98\% dos respondentes, essa experiência pedagógica contribui para a formação profissional dos alunos. Esses dados são importantes indicativos de que os PIs têm sido finalizados e avaliados com suficiente qualidade para a maioria dos docentes. No entanto, 38,9\% deles indicaram não ter promovido uma discussão com os alunos ao final da UCPI, devido à falta de tempo, e quase um quarto dos docentes afirmou que não foi possível observar a integração das competências. Essas constatações possibilitam algumas reflexões.

Em primeiro lugar, ainda que a quase totalidade dos docentes afirme ter sido possível realizar a avaliação nas premissas do Modelo Pedagógico, ao não promover 
uma devolutiva com a turma sobre o processo de desenvolvimento do $\mathrm{Pl}$, dando voz às considerações do aluno, a avaliação parece ter pendido para o caráter mais tradicional dessa prática, pelo menos para uma parte dos docentes $^{13}$. Ou seja, é provável que, para quase $40 \%$ dos docentes, as práticas avaliativas tenham apresentado maior peso em seus aspectos formais do que o dialogismo e a promoção da reflexão pelo próprio aluno, daí a tendência de os docentes priorizarem outras ações e, ao final do PI, não haver tempo suficiente para a necessária análise de todo o processo.

Em segundo lugar, chama atenção o percentual de docentes $(24,4 \%)$ que afirmou não ter sido possível observar a integração das competências do Perfil Profissional. Considerando que a integração é o propósito maior da UCPI, é possível que PIs interessantes e com resultados satisfatórios tenham sido realizados sem a necessária articulação entre as UCs, ao se priorizar uma ou outra competência.

Vale sinalizar que, no Documento Técnico, consta que a experiência da aprendizagem e a articulação das competências vivenciadas ao longo do processo são mais importantes do que os resultados em si, sendo o momento da síntese, no qual se discute com os alunos sobre o processo de realização do projeto, de grande importância pedagógica. Esses possíveis descompassos entre os objetivos pedagógicos e os resultados práticos do PI são um fenômeno que deve ser considerado nas estratégias de orientação pedagógica dos Departamentos Regionais.

\section{Figura 5 - Síntese e Avaliação segundo os docentes respondentes}

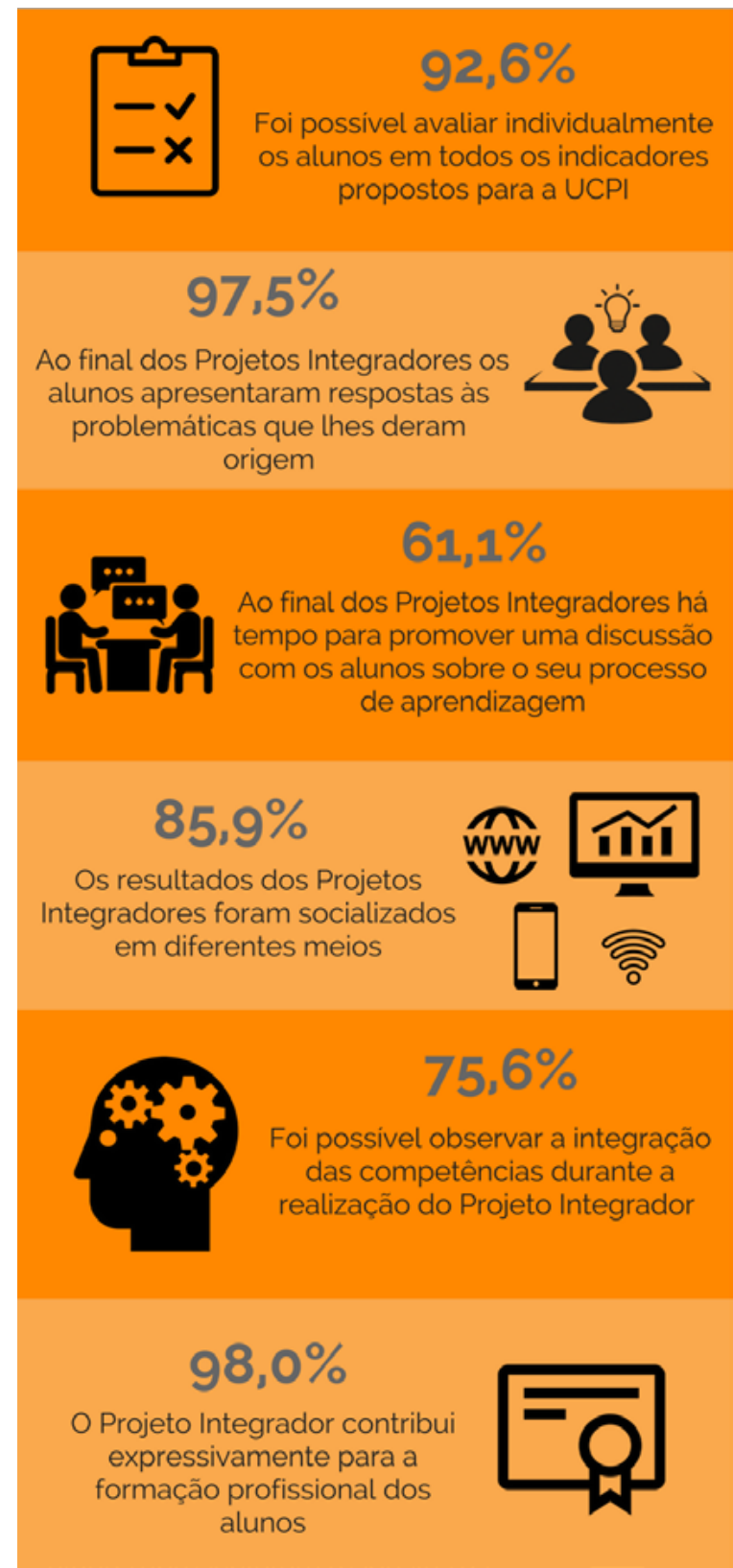

Fonte: Diretoria de Educação Profissional, Senac, Departamento Nacional. 


\subsection{Participação dos alunos}

A participação dos alunos é condição essencial para o desenvolvimento dos Projetos Integradores. Embora haja, no Documento Técnico, a orientação de a equipe pedagógica realizar um levantamento prévio de temas geradores, desenvolver uma proposta de plano de ação e definir as contribuições de cada UC, esses aspectos devem ser validados pelos alunos.

A participação
dos alunos
é condição
essencial para o
desenvolvimento
dos Projetos
Integradores

Para $87,4 \%$ dos docentes, a validação do tema gerador do PI aconteceu logo no início da UCPI. Para 92,9\%, as atividades e responsabilidades referentes ao plano de ação foram definidas em conjunto com os alunos, e o mesmo percentual de docentes afirmou que, em cada UC do curso, os alunos realizaram as atividades relacionadas ao PI. Esses números indicam que os docentes propiciaram de forma suficiente as condições pedagógicas para a participação dos alunos, com a autonomia e o protagonismo necessários para a realização dos PIs, tal qual orientado pelo Documento Técnico.

Um dado que merece atenção é que, quando arguidos sobre o interesse e empenho dos alunos no desenvolvimento dos PIs, quase a metade dos respondentes afirmou ter percebido baixo interesse e pouco empenho dos alunos no desenvolvimento dessa ação.

Uma hipótese acerca do aparente descompasso entre os resultados dos Pls e a motivação dos alunos provavelmente encontra explicação na percepção do docente em relação aos aspectos associados à dinâmica de sala de aula, tais como comportamento, disciplina e interesse dos alunos, o que pode afetar sua percepção ao avaliar o tema. Sobre esse aspecto, é importante reforçar que o Modelo Pedagógico, ao propor o alinhamento nacional dos currículos dos cursos de Habilitação Profissional Técnica, Qualificação Profissional e Aprendizagem Profissional Comercial e orientar a prática pedagógica realizada em sala de aula, conduz a mudanças substanciais no modo de fazer educação profissional no Senac. É possível que, ao trazer o aluno para o centro da cena pedagógica, a ação docente com foco no desenvolvimento de competências e a exigência do trabalho coletivo inerente à realização do PI estejam contribuindo para a superação de práticas pedagógicas enraizadas, o que, provavelmente, não está acontecendo sem conflitos.

Ainda no campo da hipótese, é possível que esse fenômeno seja percebido, tanto pelos docentes quanto pelos alunos, como uma "saída da zona de conforto", considerando que ambos os sujeitos, em menor ou maior grau, são oriundos de sistemas de educação regular nos quais ainda prevalecem práticas educacionais de características predominantemente tradicionais ${ }^{14}$. Esse elemento, no entanto, necessita de abordagem compreensiva para melhor esclarecimento. 
Figura 6 - Participação dos alunos segundo os docentes respondentes

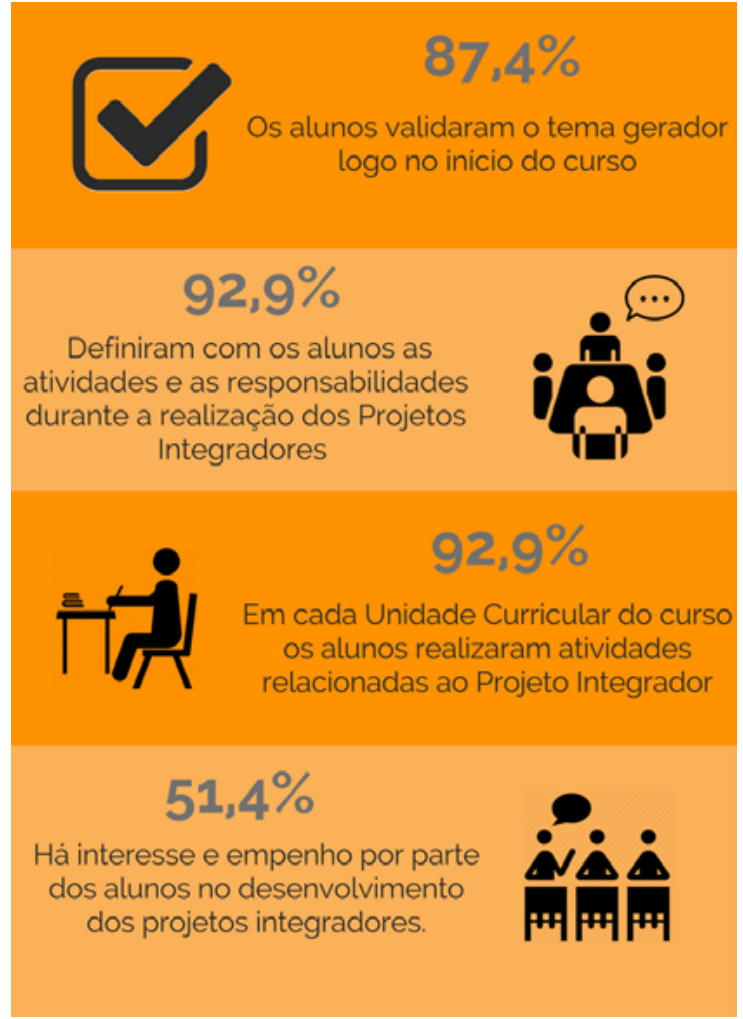

Fonte: Diretoria de Educação Profissional, Senac, Departamento Nacional.

\subsection{Participação das demais UCs para o PI}

A participação das demais UCs para a realização do PI é uma orientação explícita do Documento Técnico Planejamento Docente (SENAC, 2015e). Consta também nesse documento que, nos PTDs das UCs de um dado curso, deve ficar clara a conexão entre as competências do perfil profissional de conclusão, seus indicadores, as situações de aprendizagem descritas, os elementos e as estratégias de avaliação e, ainda, o que a UC tem a contribuir para o PI. Esse é, portanto, um ponto de atenção essencial para observância das equipes de implementação dos Departamentos Regionais, sobretudo em relação à capacidade técnica de avaliar a qualidade das atividades de insumos para a realização de PI.

Nesse sentido, $84,2 \%$ dos respondentes avaliaram como boa a participação das demais UCs para a resolução do PI; 14,5\%, como regular; e 1,3\% avaliou como ruim. Quando arguidos sobre o tipo de atividade pedagógica mais comumente utilizada pelos docentes das demais UCs como contribuição ao desenvolvimento da UCPI, encontra-se a seguinte frequência de respostas, apresentadas no quadro a seguir. 
Quadro 1 - Principais atividades de produção de insumos para a resolução do Projeto Integrador

Debates em sala de aula $(93,6 \%)$

Pesquisas na internet $(89,7 \%)$

Simulações de situações próprias do exercício da ocupação em sala de aula $(84,6 \%)$

Utilização dos laboratórios das unidades do Senac $(84,5 \%)$

Dinâmicas em sala de aula $(82,0 \%)$

Visita técnica $(40,5 \%)$

Palestras $(35,0 \%)$

Fonte: Diretoria de Educação Profissional, Senac, Departamento Nacional.

Os docentes também citaram, com menor ocorrência: brainstorming; dramatizações/teatro; jogos, como quiz; mapas mentais; pesquisa de campo; e entrevistas.

\subsection{Desenvolvimento das Marcas Formativas Senac}

Buscou-se investigar se foram realizadas, nas demais UCs, atividades para o desenvolvimento das Marcas Formativas ao longo do curso, bem como se, durante o Pl, foi possível observar seu desenvolvimento. Se, por um lado, a quase totalidade dos docentes de UCPI afirma ter proposto atividades para o desenvolvimento das Marcas Formativas Senac $(97,2 \%)$, por outro lado, $76,8 \%$ deles afirmaram ter sido possível observar o desenvolvimento das Marcas Formativas Senac.

Chama a atenção um possível descompasso entre o que é planejado em termos de atividades para o desenvolvimento das Marcas Formativas Senac e o que o docente pode observar, de fato, nos alunos. Uma hipótese a ser investigada refere-se à compreensão da prática avaliativa para verificação do desenvolvimento das Marcas Formativas na UCPI e nas demais UCs. Segundo os resultados, provavelmente, esses docentes entendem que o processo de avaliação das Marcas Formativas seja separado da avaliação das UCs, ou seja, aquela realizada por meio dos indicadores de competência, o que pode gerar, portanto, dificuldades na observação do desenvolvimento das Marcas Formativas ao longo da UCPI. A forma como os docentes 
de UCPI e os docentes das demais UCs estão avaliando o desenvolvimento das Marcas Formativas é um dado que veio à tona nesta pesquisa e que vale ser explorado pelas equipes pedagógicas nos Departamentos Regionais.

\subsection{Dificuldades dos docentes de UCPI}

No âmbito nacional, a maioria dos respondentes afirmou não ter encontrado dificuldade na execução da UCPI (68,4\%), percepção sentida de forma semelhante nos três Núcleos. No universo dos respondentes que afirmaram ter percebido dificuldades no desenvolvimento da UCPI, quando instados a identificá-las, chegou-se à seguinte listagem:

\section{Quadro 2 - Principais dificuldades relatadas pelos docentes de UCPI}

Há falta de interesse/resistência dos alunos/dificuldades de adaptação, aceitação, motivação e conscientização dos alunos $(28,1 \%)$.

Faltaram recursos necessários $(24,5 \%)$.

A carga horária do PI foi insuficiente $(10,1 \%)$.

Houve dificuldade de compreensão do PI por parte dos alunos (8\%).

Houve dificuldade de parceria com empresas e visitas técnicas (7,6\%).

Houve dificuldade na identificação das contribuições/relacionamento com as outras UCs $(7,0 \%)$.

Os problemas de relacionamento entre os alunos causaram dificuldades $(7,0 \%)$.

Houve dificuldade de entendimento dos docentes sobre a UCPI $(5,2 \%)$.

Fonte: Diretoria de Educação Profissional, Senac, Departamento Nacional.

Ao se relacionar as variáveis de capacitação docente e de dificuldade no desenvolvimento de UCPI, detecta-se que, entre os docentes que disseram ter dificuldades na execução da UCPI, 78 (24,2\%) não leram o documento de referência do PI da Coleção de Documentos Técnicos do MPS, sendo que 37 docentes desse grupo $(47,4 \%)$ também não participaram de nenhuma ação de formação docente.

Como visto anteriormente, a leitura do Documento Técnico e a participação em ações de formação docente, ainda que associadas em algum grau à aderência da UCPI, não aparecem, necessariamente, como fator vinculado às dificuldades perce- 
bidas pelos docentes. Novamente, a relação docente-aluno aparece nos relatos dos respondentes, dessa vez percebida como fator de maior dificuldade para o desenvolvimento de Pls. Decerto que esse dado sinaliza a necessidade de maior atenção quanto à implementação de ações e programas que busquem criar condições facilitadoras para as situações de ensino e aprendizagem na educação profissional, mas, também, não se pode deixar de mencionar que, em certa medida, esse fenômeno espelha um quadro atual do panorama educacional brasileiro, no qual pesam questões de baixo desempenho e atraso escolar, além do descompasso entre os interesses dos alunos e as práticas pedagógicas desenvolvidas na escola ${ }^{15}$.

Considerando que, ao propor práticas centradas em metodologias ativas da aprendizagem, o MPS coloca o aluno para o centro da ação educativa, é esperado que, nesse momento de transição didático-pedagógica, as dificuldades percebidas pelos docentes sejam, justamente, de natureza relacional.

\section{Considerações finais}

Com média nacional de 8,33 pontos de aderência das práticas pedagógicas da UCPI ao MPS, é possível concluir que os PIs, na qualidade de importante ação do MPS, vêm sendo implementados a contento nos Departamentos Regionais. Entretanto, alguns aspectos merecem especial atenção.

Os resultados evidenciaram a importância das ações de formação continuada desenvolvidas junto aos docentes, elemento diretamente associado à qualidade da prática docente. O desafio, portanto, é a implementação de ações de impacto formativo que tenham aproveitamento imediato e bom custo-benefício. Para os Departamentos Regionais, recomendam-se a ampla divulgação dos Documentos Técnicos de Referência do Modelo Pedagógico e a elaboração, por parte das equipes pedagógicas, de Pré-Planos de Trabalho Docente, tanto da UCPI do próprio docente quanto das demais UCs, já que essa estratégia foi considerada importante variável para o bom desenvolvimento de PIs.

Um ponto a se destacar refere-se à potência dos Projetos Integradores em apresentar, por resultados, possíveis soluções inovadoras. A inovação é um valor no Senac, logo, é preciso organizar estratégias que promovam e impulsionem de forma permanente a cultura de inovação na Instituição. Os PIs, nesse sentido, tendem a ser um caminho promissor, sobretudo se seus temas geradores estiveram alinhados às questões reais do setor produtivo local. Outras instituições que integram os Serviços Sociais Autônomos têm demonstrado experiências promissoras de Pls como fonte de inovação ${ }^{16}$. No entanto, destaca-se que ainda que os resultados tenham evidenciado a potencialidade de estímulo à inovação pela via dos PIs, a UCPI tem por foco a natureza pedagógica da articulação das competências do perfil profissional dos cursos.

Por último, um aspecto que necessita de maior reflexão qualitativa, dados os limites deste trabalho, repousa no descompasso entre o interesse dos alunos e a sua participação. Na avaliação dos docentes, conforme visto nos resultados, uma das principais 
dificuldades declaradas na execução da UCPI foi a falta de interesse e motivação dos alunos. No entanto, os docentes reconhecem a boa participação dos estudantes. Essa contradição deve ser mais bem investigada, tendo como público-alvo, para futuras abordagens, os alunos que participaram dos Pls.

\section{Notas}

1 Trata-se, esta pesquisa, de uma ação intergerencial realizada pelas gerências de Prospecção e Avaliação Educacional e Desenvolvimento Educacional, da Diretoria de Educação Profissional do Departamento Nacional do Senac.

${ }^{2}$ As Marcas Formativas são características a serem evidenciadas nos alunos ao longo do processo formativo. Derivam dos princípios educacionais e valores institucionais que regem o Modelo Pedagógico Senac e, por essa via, representam o compromisso da Instituição com a formação integral do profissional cidadão. Como Marcas Formativas, espera-se que o profissional formado pelo Senac evidencie domínio técnico-científico em seu campo profissional, tenha visão crítica sobre a realidade e as ações que realiza e apresente atitudes empreendedoras, sustentáveis e colaborativas, atuando com foco em resultados (SENAC, 2015c, p. 15).

${ }^{3}$ Segundo dados da produção Senac/DN Dezembro/2017.

${ }^{4}$ Integra a Coleção de Documentos Técnicos do Modelo Pedagógico Senac. Disponível em <http://www.extranet.senac.br/modelopedagogicosenac/index.html>.

${ }^{5}$ Sobre indicadores de avaliação, para Projeto Integrador e demais Unidades Curriculares, conferir: Senac (2015a).

${ }^{6}$ Sobre situações de aprendizagem e plano de trabalho docente, conferir Documento Técnico Planejamento Docente (SENAC, 2015d).

${ }^{7}$ A Coleção de Documentos Técnicos foi elaborada de forma colaborativa, com a participação de todos os Departamentos Regionais. É composta, atualmente, por nove volumes que versam sobre os temas centrais do Modelo Pedagógico Senac. Está disponível no link: <http://www.extranet.senac.br/modelopedagogicosenac/index.html>.

${ }^{8}$ Pesquisa realizada com fins práticos, movida pela necessidade do conhecimento para aplicação imediata de resultados (ROLL-HANSEN, 2009).

${ }^{9} \mathrm{O}$ erro amostral é a diferença entre o resultado obtido na amostra e o real valor populacional.

${ }^{10}$ Software de estruturação de questionários on-line e coleta de respostas.

${ }^{11}$ Foi realizada a compatibilização das respostas quando se previa que o respondente discordasse, total ou parcialmente, de alguma assertiva.

${ }^{12}$ Sobre Teoria da Mudança, consultar Lima (2003).

${ }^{13}$ Segundo o Documento Técnico Avaliação da Aprendizagem, a devolutiva da avaliação, momento em que o docente debate os resultados em conjunto com o aluno, é ponto que merece especial atenção para incremento de qualidade no ato avaliativo. Na educação profissional, a devolutiva deve ser norteada pelo desenvolvimento da competência 
e ter por pauta o atendimento aos seus indicadores, sendo realizada de forma precisa e construtiva. Por esse sentido, a ação de refletir acerca dos resultados junto ao aluno, analisando em conjunto quais os ganhos e quais os aspectos que ainda devem ser melhorados e as diversas formas de atingi-los, contribui sobremaneira para o desenvolvimento pleno das competências do perfil profissional (SENAC, 2015a).

${ }^{14} \mathrm{~A}$ abordagem tradicional de ensino ainda é comum nas escolas de ensino regular no Brasil. Nesse tipo de abordagem, o foco está no professor, que detém conhecimentos e os repassa ao aluno, geralmente, em aulas expositivas. O estudante tem metas a cumprir dentro de determinados prazos, que são verificadas por meio de avaliações periódicas. Nessa perspectiva, priorizam-se o acúmulo de conhecimento e o sucesso do aluno em avaliações como o Exame Nacional do Ensino Médio (Enem) e o vestibular (CORDEIRO; OLIVEIRA, 2015).

${ }^{15}$ Sobre esse tema, cf. Anuário Brasileiro de Educação Básica, disponível em <https:// www.todospelaeducacao.org.br//arquivos/biblioteca/anuario_educacao_2016.pdf>.

16 Um exemplo é o Desafio Senai de Projetos Integradores, lançado pelo Serviço Nacional de Aprendizagem Industrial em 2015. Para mais informações, consultar <portaldaindustria.com.br/senai/canais/desafio-senai-de-projetos-integradores $>$.

\section{Referências}

ALVES-MAZZOTTI, A. J.; GEWANDSZNAJDER, F. 0 método nas ciências naturais e sociais. São Paulo: Pioneira, 2004.

ANUÁRIO brasileiro de educação básica 2016. São Paulo: Moderna, 2016. Disponível em: <https://www.todospelaeducacao.org.br//arquivos/biblioteca/ anuario_educacao_2016.pdf>. Acesso em: 22 nov. 2017.

BARDIN, L. Análise de conteúdo. Lisboa: Edições 70, 2009.

BOGDAN, R.; BIKLEN, S. Investigação qualitativa em educação. Porto: Porto Ed., 1994.

CORDEIRO, E. M.; OLIVEIRA, G. S. As metodologias de ensino predominantes nas

salas de aula. Uberaba, 2015. Trabalho apresentado no Congresso Internacional Trabalho Docente e Processos Educativos, 3., 2015, Uberaba. Disponível em <https:// www.uniube.br/eventos/epeduc/2015/completos/23.pdf>. Acesso em: 15 dez. 2017.

KILPATRICK, W. H. Educação para uma civilização em mudança. 5. ed. São Paulo: Melhoramentos, 1967.

LAROS, J. A.; PUENTE-PALACIOS, K. E. Validação cruzada de uma escala de clima organizacional. Estudos de Psicologia (Natal), Natal, v. 9, n. 1, p. 113-119, abr. 2004.

LIMA, S. M. V. Mudança organizacional: teoria e gestão. Rio de Janeiro: Ed. FGV, 2003. 
ORGANIZAÇÃO PARA COOPERAÇÃO E DESENVOLVIMENTO ECONÔMICO.

Manual de Oslo: diretrizes para coleta e interpretação de dados sobre inovação. 3. ed. Rio de Janeiro: Finep, 2017. Disponível em <http://www.finep.gov.br/images/ apoio-e-financiamento/manualoslo.pdf>. Acesso em: 25 dez. 2017.

ROLL-HANSEN, N. Why the distinction between basic (theoretical) and applied (practical) research is important in the politics of science. London: CPNSS, 2009. Disponivel em: <https://pdfs.semanticscholar.org/62f0/ dced123c24c7bc89b7d0d72bfcf885634a43.pdf>. Acesso em: 22 nov. 2017.

SENAC. DN. Avaliação da aprendizagem. Rio de Janeiro, 2015a. (Coleção de Documentos Técnicos do Modelo Pedagógico Senac, 5). Disponível em: <http:// www.extranet.senac.br/modelopedagogicosenac/arquivos/DT_5_Avaliacao\%20 da\%20Aprendizagem.pdf>. Acesso em: 3 out. 2018.

SENAC. DN. Competência. Rio de Janeiro, 2015b. (Coleção de Documentos Técnicos do Modelo Pedagógico Senac, 2). Disponível em: <http://www.extranet.senac.br/ modelopedagogicosenac/arquivos/DT_2_Competencia.pdf>. Acesso em: 1 out. 2018.

SENAC. DN. Concepções e princípios. Rio de Janeiro, 2015c. (Coleção de Documentos Técnicos do Modelo Pedagógico Senac, 1). Disponível em: <http:// www.extranet.senac.br/modelopedagogicosenac/arquivos/DT_1_Concepcoes\%20 e\%20Principios.pdf>. Acesso em: 1 out. 2018.

SENAC. DN. Metodologias ativas da aprendizagem. Rio de Janeiro, 2018. (Coleção de Documentos Técnicos do Modelo Pedagógico Senac, 7). Disponível em: <http://www.extranet.senac.br/modelopedagogicosenac/arquivos/Doc_ Metodologias\%20Ativas_final.pdf>. Acesso em: 4 jan. 2018.

SENAC. DN. Planejamento docente. Rio de Janeiro, 2015d. (Coleção de Documentos Técnicos do Modelo Pedagógico Senac, 3). Disponível em: $<$ http://www.extranet.senac.br/modelopedagogicosenac/arquivos/DT_3_ Planejamento\%20Docente.pdf>. Acesso em: 3 out. 2018.

SENAC. DN. Projeto integrador. Rio de Janeiro, 2015e. (Coleção de Documentos Técnicos do Modelo Pedagógico Senac, 4). Disponível em: <http://www.extranet. senac.br/modelopedagogicosenac/arquivos/DT_4_Projeto\%20Integrador.pdf>. Acesso em: 1 out. 2018.

TUCKMAN, B. Manual de investigação em educação. Lisboa: Fundação Calouste Gulbenkian, 2005.

URBINA, S. Fundamentos da testagem psicológica. Porto Alegre: Artmed, 2007. 